\title{
Coarctectomy combined with an interdigitating arch reconstruction results in a lower incidence of recurrent arch obstruction after the Norwood procedure than coarctectomy alone
}

\author{
Luke J. Lamers, MD, ${ }^{\mathrm{a}, \mathrm{c}}$ Peter C. Frommelt, MD, ${ }^{\mathrm{a}, \mathrm{c}}$ Kathleen A. Mussatto, RN, PhD, ${ }^{\mathrm{c}}$ \\ Robert D. B. Jaquiss, MD, ${ }^{\mathrm{b}, \mathrm{c}}$ Michael E. Mitchell, MD, ${ }^{\mathrm{b}, \mathrm{c}}$ and James S. Tweddell, MD ${ }^{\mathrm{a}, \mathrm{b}, \mathrm{c}}$
}

\begin{abstract}
Objective: Recurrent aortic arch obstruction after the Norwood procedure continues to be a source of morbidity. We sought to determine if a modified interdigitating technique for aortic arch reconstruction during the Norwood procedure decreased recurrent arch obstruction.
\end{abstract}

\begin{abstract}
Methods: A total of 142 consecutive infants undergoing the Norwood procedure were divided into groups according to surgical technique: Group $1(n=79$, January 1999 to May 2003) underwent arch reconstruction with complete coarctectomy followed by anastomosis of the descending aorta to the transverse arch. Group 2 ( $n=63$, June 2003 to September 2006) underwent complete coarctectomy plus a modified interdigitating technique. Catheterization before stage 2 palliation was reviewed for hemodynamics and angiographic arch dimensions, and a coarctation index was calculated.
\end{abstract}

Results: Reintervention for recurrent coarctation occurred in 28\% (22/79) of group 1 patients compared with $2 \%(1 / 63)$ of group 2 patients $(P=.001)$. Aortic pressures, gradients, dimensions, and coarctation index were consistently more favorable for group 2 .

Conclusions: Coarctectomy plus an interdigitating arch anastomosis was superior to coarctectomy alone and resulted in a dramatically decreased incidence of recurrent arch obstruction. (J Thorac Cardiovasc Surg 2012;143:1098-102)

\section{Earn CME credits at}

http://cme.ctsnetjournals.org

The documented incidence of recurrent coarctation of the aorta after the Norwood procedure (NP) ranges from $5 \%$ to $40 \%{ }^{1-5}$ Factors contributing to recoarctation include surgical technique and contraction of residual ductal tissue not resected at the time of the NP. Several modifications have been made to the original arch reconstruction technique described by Norwood and colleagues, ${ }^{6}$ yet the incidence of recoarctation and its resultant morbidity remain significant. The increased afterload to the single ventricle caused by recoarctation may result in ventricular dysfunction and atrioventricular valve regurgitation, increasing the risk of morbidity and mortality. This

\footnotetext{
From the Section of Pediatric Cardiology, ${ }^{\mathrm{a}}$ Department of Pediatrics, Division of Car-

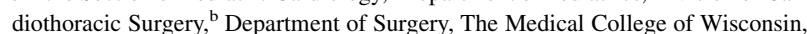
Milwaukee, Wis; and the Herma Heart Center at the Children's Hospital of Wisconsin, ${ }^{\mathrm{c}}$ Milwaukee, Wis.

Disclosures: Authors have nothing to disclose with regard to commercial support.

Received for publication June 5, 2010; revisions received Sept 5, 2011; accepted for publication Sept 26, 2011; available ahead of print Nov 4, 2011

Address for reprints: James S. Tweddell, MD, Children's Hospital of Wisconsin, 9000 West Wisconsin Ave, Milwaukee, WI 53226 (E-mail: jtweddell@chw.org). $0022-5223 / \$ 36.00$

Copyright (c) 2012 by The American Association for Thoracic Surgery doi:10.1016/j.jtcvs.2011.09.037
}

article describes the incidence of recoarctation after the NP in a recent cohort of patients with single ventricle physiology at the Children's Hospital of Wisconsin and to identify factors contributing to long-term arch patency after aortic arch reconstruction in children with significant systemic outflow obstruction.

\section{MATERIALS AND METHODS}

The clinical records of 142 consecutive infants undergoing the NP at the Children's Hospital of Wisconsin between January 1999 and September of 2006 were reviewed after institutional review board approval. The focus of this retrospective analysis was to determine the difference in the incidence of recurrent obstruction using 2 different techniques of arch reconstruction. In all 142 patients, a coarctectomy was performed as part of the arch reconstruction. Before June of 2003, the posterior edge of the descending thoracic aorta was sutured to the posterior edge of the distal arch without interdigitation. Beginning in June of 2003, the interdigitating arch reconstruction technique was added. This surgical procedure has been described. ${ }^{1,7}$ Briefly, our interdigitating technique is as follows: The hypoplastic aorta, brachiocephalic vessels, ductus arteriosus, and pulmonary arteries are fully mobilized. A polytetrafluoroethylene (GoreTex; WL Gore \& Associates Inc, Flagstaff, Ariz) graft is anastomosed to the innominate artery that is used for arterial cannulation for cardiopulmonary bypass and subsequent cerebral perfusion during arch reconstruction and becomes the systemic-to-pulmonary artery shunt in patients undergoing a classic NP. Mobilization of the proximal descending aorta is assisted by division of the first 2 to 3 sets of intercostal arteries. After cooling to a bladder temperature of $18^{\circ} \mathrm{C}$, a brief period of circulatory arrest averaging 10 minutes occurs to administer cardioplegia and perform an atrial septectomy. Regional cerebral perfusion is then initiated via the innominate artery shunt. The aortic isthmus is divided. The pulmonary artery side of the ductus arteriosus is ligated, and all ductal tissue is resected 


\section{Abbreviation and Acronym}

$\mathrm{NP}=$ Norwood procedure

from the descending aorta. Two indicators are used to ensure that all ductal tissue is excised. First, the arterial wall of the ductus is thicker and the tissue is more friable than that of native descending aortic tissue, and excision is continued until thin tissue characteristic of the descending aorta is reached. Second, the ductal tissue excision is continued to within 1 to $2 \mathrm{~mm}$ of the first set of intercostal arteries because the intercostal arteries arise from the descending aorta and not the ductus arteriosus; this indicates complete ductal excision. The undersurface of the aortic arch is then incised from the divided isthmus proximally down the hypoplastic ascending aorta, and a cutback in the pulmonary root is made at a precise site allowing for creation of a nonstenotic anastomosis between the aortic and pulmonary root. A cutback is made in the posterior left lateral descending thoracic aorta. The open distal arch is then sutured within the cutback in the

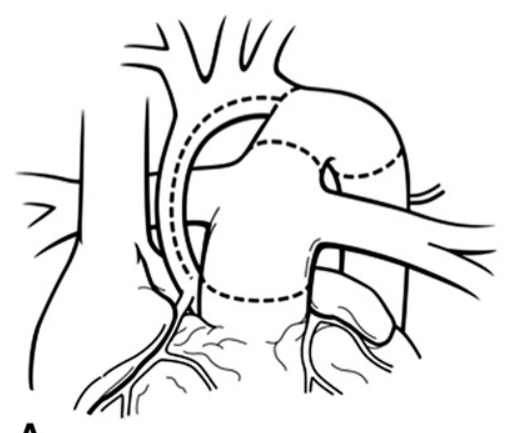

A
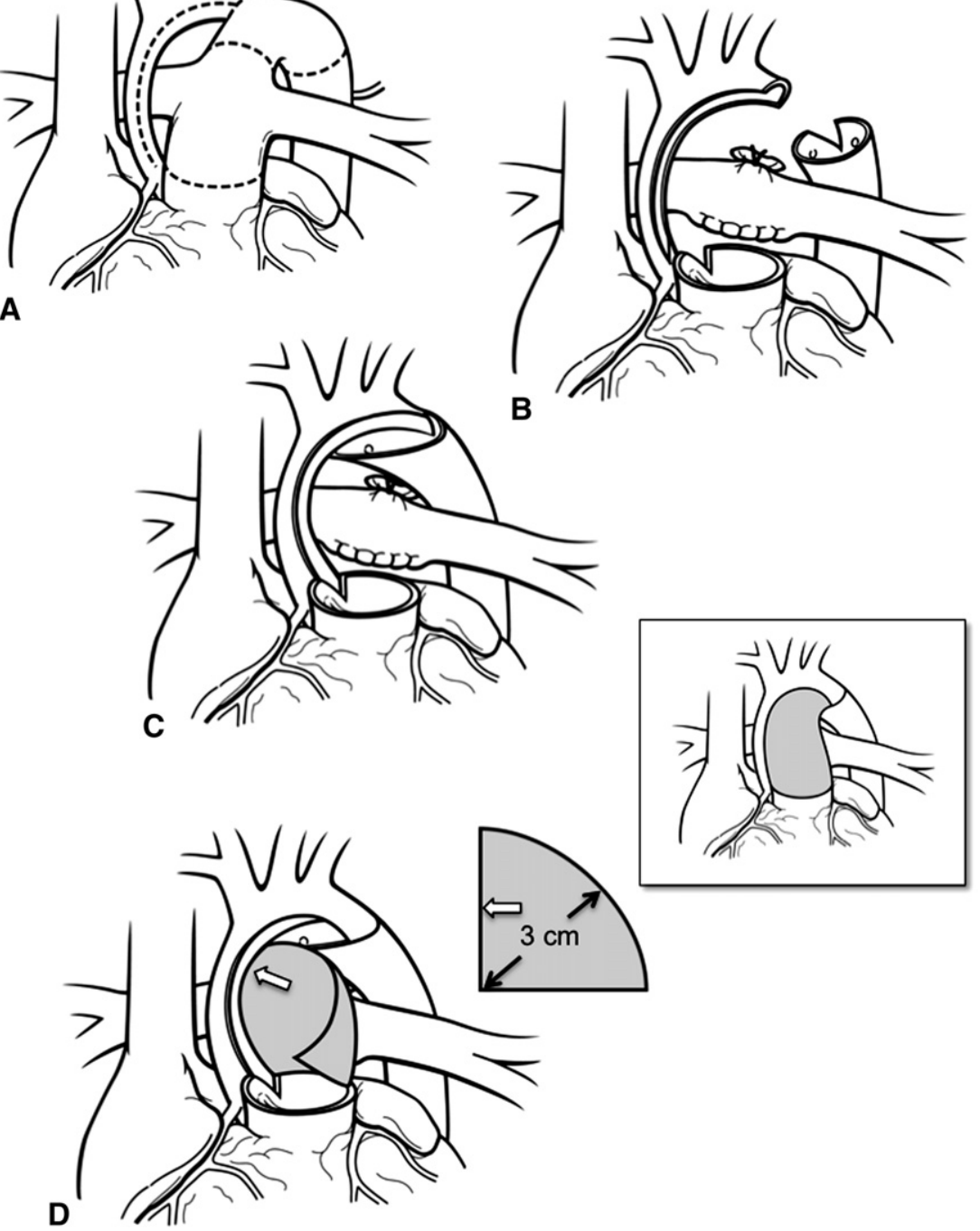

FIGURE 1. Coarctectomy combined with an interdigitating arch reconstruction. A, Preoperative anatomy. Dotted lines indicate the areas to be incised. $\mathrm{B}$, The aortic isthmus is divided, and all ductal tissue is excised. The undersurface of the arch is incised, and this incision is carried down the medial aspect of the ascending aorta. Cutbacks are performed in the posterior left lateral aspect of the proximal descending aorta and the pulmonary root leftward of the commissure that is adjacent to the ascending aorta. C, Large interdigitating tissue-to-tissue connection is created between the open distal arch and the descending aorta. The descending aorta can be brought as far proximally as the distal ascending aorta. Finally, the adjacent points of the ascending aorta and pulmonary root cutback are sutured together. D, Patch of homograft material is used to complete the arch reconstruction and neoascending aorta. A flat piece of homograft material is used that is in the shape of a quarter of a circle with a radius of $3 \mathrm{~cm}$. The straight edge of the graft (open arrow) is sutured to the inner curvature, and the curved outer edge of the patch is sutured to the outer curvature. The patch is tailored as the suture-line transitions to the pulmonary root. Although a large portion of the original patch may be trimmed away, the $3-\mathrm{cm}$ radius ensures that the neoascending aorta will be without obstruction because this corresponds to the circumference of the typical pulmonary root of the typical patient undergoing the NP. The final reconstruction is shown in the inset. 
TABLE 1. Patient demographics

\begin{tabular}{lccc}
\hline & $\begin{array}{c}\text { Group 1 } \\
\text { NP January } \\
\text { 1999 to May 2003 }\end{array}$ & $\begin{array}{c}\text { Group 2 } \\
\text { NP June 2003 to } \\
\text { September 2006 }\end{array}$ & P value \\
\hline No. of patients & 79 & 63 & \\
Male (\%) & $48(61)$ & $39(62)$ & .9 \\
Age at NP $(\mathrm{d})$ & $6.1 \pm 4.1$ & $7.6 \pm 7.7$ & .13 \\
Weight at NP $(\mathrm{kg})$ & $3.1 \pm 0.5$ & $3.3 \pm 0.6$ & .16 \\
Height at NP $(\mathrm{cm})$ & $49.9 \pm 3.0$ & $50.2 \pm 6.7$ & .76 \\
\hline
\end{tabular}

descending thoracic aorta in an interdigitating fashion creating a large native tissue-to-tissue connection. Pulmonary homograft tissue is used to complete the construction of the neoaorta. The technique of arch reconstruction is shown in Figure 1. The systemic to pulmonary artery shunt, whether a modified Blalock-Taussig shunt or a right ventricle to pulmonary artery conduit, is constructed during rewarming. The total cohort of patients for this study was divided into 2 chronologic groups, those undergoing the NP between January 1999 and May of 2003 without an interdigitating arch reconstruction (group $1, \mathrm{n}=79$ ) and those undergoing the NP between June 2003 and September of 2006 with an interdigitating arch reconstruction (group 2, $\mathrm{n}=63$ ).

Demographics and primary diagnosis of the 2 groups at the NP as defined by echocardiography are detailed in Tables 1 and 2. Clinical records were reviewed for any reinterventions after the NP (surgical or balloon dilation/stenting) to address aortic arch or brachiocephalic vessel anatomic or physiologic abnormalities. Timing of these reinterventions in relation to the NP was recorded.

Angiography from cardiac catheterization before stage 2 palliation was reviewed. Neoaortic dimensions were recorded in the following positions: neoaortic valve, neoaortic sinuses, point of maximal dimension of the ascending neoaorta in both the anterior-posterior and lateral views, transverse neoaortic arch, distal neoaortic arch anastomosis, proximal descending aorta, and aorta at the diaphragm. The coarctation index was calculated as the ratio of the narrowest arch segment divided by the diameter of the aorta at the level of the diaphragm. ${ }^{8}$ Blood pressure measured directly in the ascending and descending aorta and pulmonary and systemic flow measurements were recorded from catheterization reports.

\section{Statistical Analysis}

Results are expressed as mean \pm standard deviation or median with ranges as appropriate. Data were analyzed using SPSS 13.0 statistical software (SPSS Inc, Chicago, Ill). A descriptive analysis of the sample was performed. Continuous variables were compared using Student $t$ tests (mean \pm standard deviation) and Mann-Whitney test (median and range). Categoric variables were compared using chi-square technique.

TABLE 2. Patient diagnostic groups

\begin{tabular}{|c|c|c|c|c|}
\hline \multirow[b]{2}{*}{ Diagnostic group } & \multicolumn{2}{|c|}{ Group 1} & \multicolumn{2}{|c|}{ Group 2} \\
\hline & $\mathbf{n}$ & $(\%)$ & $\mathbf{n}$ & $(\%)$ \\
\hline Hypoplastic left heart syndrome & 65 & 82 & 52 & 83 \\
\hline Double-inlet left ventricle with coarctation & 3 & 4 & 2 & 3 \\
\hline Right ventricular hypoplasia with TGA & 6 & 8 & 3 & 5 \\
\hline $\begin{array}{l}\text { Right dominant unbalanced } \\
\text { atrioventricular septal defect }\end{array}$ & 1 & 1 & 2 & 3 \\
\hline $\begin{array}{l}\text { Double-outlet right ventricle with left } \\
\text { ventricular hypoplasia }\end{array}$ & 4 & 5 & 3 & 5 \\
\hline $\begin{array}{l}\text { Interrupted aortic arch with left ventricular } \\
\text { hypoplasia }\end{array}$ & & & 1 & 2 \\
\hline
\end{tabular}

$T G A$, Transposition of the great arteries.
TABLE 3. Catheterization hemodynamics

\begin{tabular}{lccc}
\hline & Group 1 & Group 2 & $\boldsymbol{P}$ value \\
\hline $\begin{array}{l}\text { Ascending aorta systolic blood } \\
\text { pressure (mm Hg) }\end{array}$ & $93.0 \pm 16.3$ & $77.9 \pm 13.9$ & .001 \\
$\begin{array}{l}\text { Ascending aorta diastolic blood } \\
\quad \text { pressure (mm Hg) }\end{array}$ & $34.1 \pm 6.6$ & $32.9 \pm 4.9$ & .25 \\
$\begin{array}{l}\text { Ascending aorta mean blood } \\
\text { pressure (mm Hg) }\end{array}$ & $57.7 \pm 9.4$ & $50.6 \pm 7.6$ & .001 \\
$\begin{array}{l}\text { Descending aorta systolic blood } \\
\quad \text { pressure (mm Hg) }\end{array}$ & $84.8 \pm 13.7$ & $75.6 \pm 16.2$ & .001 \\
$\begin{array}{l}\text { Descending aorta diastolic blood } \\
\text { pressure (mm Hg) }\end{array}$ & $33.9 \pm 6.9$ & $32.9 \pm 4.4$ & .37 \\
$\begin{array}{l}\text { Descending aorta mean blood } \\
\quad \text { pressure (mm Hg) }\end{array}$ & $54.3 \pm 8.9$ & $49.2 \pm 7.5$ & .001 \\
$\begin{array}{l}\text { Systolic blood pressure gradient } \\
\text { Diastolic blood pressure gradient }\end{array}$ & $0.46 \pm 2.3 \pm 14.3$ & $2.5 \pm 7.5$ & .005 \\
\begin{tabular}{l} 
Mean blood pressure gradient \\
\hline
\end{tabular} & $3.5 \pm 4.0$ & $0.3 \pm 2.6$ & .62 \\
& & & .001 \\
\hline
\end{tabular}

\section{RESULTS}

Hypoplastic left heart syndrome made up the majority of patients in group $1(82 \%)$ and group $2(83 \%)$ (Table 2 ). The frequency of aortic and mitral atresia was similar for the 2 groups $(42 \%$ vs. $36 \%, P=.5)$ as was the size of the ascending aortic dimensions measured by preoperative echocardiogram $(3.5 \pm 1.7 \mathrm{~mm}$ vs. $3.6 \pm 1.7 \mathrm{~mm}, P=.8)$. Thirty-three percent of group 1 and $36 \%$ of group 2 patients had ascending aortas measuring $2 \mathrm{~mm}$ or less $(P=.7)$. Patient age, weight, height, and gender distribution at the time of the NP was similar for the 2 groups. All patients in group 1 had Blalock-Taussig shunts; 49\% (31/ 63) of group 2 patients had right ventricle to pulmonary artery conduits.

Prestage 2 palliation catheterizations were performed at a younger age in group 2 patients $(3.3 \pm 1.0$ months vs. $3.8 \pm$ 1.4 months, $P=.03$ ); however, height, weight, and body surface area were similar for the 2 groups. Group 1 patients had increased systolic and mean blood pressure in the ascending aorta and increased systolic and mean blood pressure gradients from the ascending to descending aorta (Table 3). Diastolic blood pressures were similar for the 2 groups in the ascending and descending aortas. All patients were able to maintain mean pressures in the descending aorta greater than $40 \mathrm{~mm} \mathrm{Hg}$ regardless of the angiographic or hemodynamic severity of recoarctation. For all patients who underwent reintervention $(16 \%, \mathrm{n}=23 / 142)$, the average systolic blood pressure gradient was $22.6 \pm 17.6 \mathrm{~mm}$ $\mathrm{Hg}$ compared with $2.1 \pm 5.9 \mathrm{~mm} \mathrm{Hg}$ for those who did not undergo reintervention $(P<.001)$.

Angiographic measurements of the aortic arch are shown in Table 4. Group 1 patients had increased dimensions at the neoaortic sinus, proximal descending aorta, and aorta at the diaphragm, and decreased transverse arch and distal neoaortic arch anastomosis dimensions. The coarctation index was greater in group 2 patients. 
TABLE 4. Angiographic dimensions

\begin{tabular}{lccc}
\hline & Group 1 & Group 2 & $\boldsymbol{P}$ value \\
\hline Neoaortic valve (mm) & $12.2 \pm 2.3$ & $11.7 \pm 2.2$ & .23 \\
Neoaortic sinus (mm) & $17.7 \pm 3.5$ & $16.2 \pm 2.1$ & .004 \\
Ascending neoaorta maximal & $17.4 \pm 3.5$ & $17.2 \pm 3.5$ & .76 \\
$\quad$ dimension anterior- & & & \\
$\quad$ posterior (mm) & & & \\
Ascending neoaorta maximal & $17.0 \pm 4.2$ & $16.5 \pm 2.8$ & .53 \\
$\quad$ dimension lateral (mm) & & & \\
Transverse arch (mm) & $10.3 \pm 2.5$ & $11.6 \pm 2.4$ & .009 \\
Distal neoaortic arch & $6.2 \pm 1.9$ & $6.8 \pm 1.4$ & .04 \\
$\quad$ anastomosis (mm) & & & \\
Proximal descending aorta (mm) & $7.8 \pm 1.7$ & $6.3 \pm 1.0$ & .001 \\
Aorta at diaphragm (mm) & $8.1 \pm 1.3$ & $6.8 \pm 0.9$ & .001 \\
Coarctation index & $0.8(0.3-1.7)$ & $1.0(0.4-1.7)$ & .001 \\
Recoarctation intervention, $\mathrm{n}(\%)$ & $22(28)$ & $1(2)$ & .001 \\
\hline
\end{tabular}

Reintervention for recoarctation was performed in $28 \%$ (22/79) of group 1 patients at a median age of 116 days (range, 43-1091 days). Three patients were effectively palliated with balloon dilation, 4 patients had balloon dilation followed by surgical arch reconstruction, and 15 patients had surgical repair at the time of stage 2 palliation. The incidence of reintervention for recoarctation in group 2 patients was $2 \%(1 / 63)$. This patient underwent successful balloon dilation of the recoarctation at 4 months of age. No additional arch surgeries were necessary in group 2 patients. Hypoplastic left heart syndrome was the primary diagnosis in $91 \%(21 / 23)$ of patients with recoarctation. Survival through stage 2 palliation were similar for the 2 groups, as is current survival for group $1(82 \%)$ and group $2(84 \%)$ patients.

\section{DISCUSSION}

Obstruction to systemic blood flow is poorly tolerated in infants with single ventricle physiology who have undergone the NP. In these patients, the single ventricle is responsible for pumping blood to both the pulmonary and systemic circulation, and any obstruction to flow worsens an already inefficient system of parallel circulation. Recoarctation increases systemic resistance, resulting in excessive pulmonary blood flow with increased volume load and increased wall stress to a single ventricle with limited reserve. Even mild arch obstruction can lead to ventricular dysfunction, increased atrioventricular valve regurgitation, and diminished systemic perfusion. Fraisse and colleagues ${ }^{9}$ also showed that residual arch obstruction significantly increases the risk for mortality. Previous studies document the frequency of recoarctation to be in the range of $10 \%$ to $40 \% .^{1-5}$

Recurrent arch obstruction seems to be affected by both surgical technique and failure to completely resect ductal tissue from the aorta before completion of the arch reconstruction. ${ }^{10}$ This series compares 2 groups in which complete coarctectomy was performed. With each technique, care was taken to completely resect all ductal tissue before completing the arch reconstruction. In addition to coarctectomy, our current technique uses an interdigitating technique in which the open distal transverse arch is sutured into a cutback in the posterior left lateral descending thoracic aorta. This results in a large native tissue-to-tissue connection similar to an extended end-to-end coarctation repair. With this technique, the incidence of recurrent aortic arch obstruction has dramatically decreased to $2 \%$ in patients undergoing the NP since June 2003 compared with an approximate $30 \%$ incidence in patients undergoing operation before use of the interdigitating technique.

Burkhart and colleagues ${ }^{1}$ reported similar results with the interdigitating technique. In their study, 3 surgical techniques used in different eras were compared. The initial group of patients underwent a classic NP with incision across the coarctation followed by patch reconstruction with homograft tissue. The incidence of recoarctation with this technique was $46 \%$. The second group of patients underwent arch reconstruction with an autologous technique described initially by Fraser and Mee. ${ }^{11}$ With this technique, all ductal tissue is resected and the arch is reconstructed by anastomosing the distal aorta, aortic arch, and main pulmonary artery together. This group of patients had a recoarctation rate of $15 \%$. Finally, the most recent 33 patients underwent an interdigitating technique, and the incidence of recoarctation was $0 \%$.

\section{Limitations}

This was a retrospective study comparing noncontemporary groups, with all the limitations of that study design. A learning curve and greater surgeon experience may have contributed to the improved results in the later group of patients.

\section{CONCLUSIONS}

Avoidance of recurrent arch obstruction is an important goal in the treatment of patients requiring the NP. Coarctectomy plus an interdigitating arch anastomosis was superior to coarctectomy alone, resulting in a dramatically decreased incidence of recurrent arch obstruction, and is the technique of choice for the NP.

\section{References}

1. Burkhart H, Ashburn D, Konstantinov I, De Oliviera N, Benson L, Williams W, et al. Interdigitating arch reconstruction eliminates recurrent coarctation after the Norwood procedure. J Thorac Cardiovasc Surg. 2005;130:61-5.

2. Ishino K, Stumper O, De Giovanni J, Silove E, Wright J, Sethia B, et al. The modified Norwood procedure for hypoplastic left heart syndrome: early to intermediate results of 120 patients with particular reference to aortic arch repair J Thorac Cardiovasc Surg. 1999;117:920-30.

3. Chessa M, Dindar A, Vettukattil J, Stumper O, Wroght J, Silove E, et al. Balloon angioplasty in infants with arch obstruction after the modified stage I Norwood procedure. Am Heart J. 2000;140:227-31. 
4. Tworetzky W, McElhinney D, Burch G, Teitel D, Moore P. Balloon arterioplasty of recurrent coarctation after the modified Norwood procedure in infants. Cathet Cardiovasc Intervent. 2000;50:54-8.

5. Zellers T. Balloon angioplasty for recurrent coarctation of the aorta in patients following staged palliation for hypoplastic left heart syndrome. Am J Cardiol. 1999;84:231-2.

6. Norwood W, Lang P, Hansen D. Physiologic repair of aortic atresia-hypoplastic left heart syndrome. N Engl J Med. 1983;306:23-6.

7. Tweddell J. The Norwood procedure with an innominate artery-to-pulmonary artery shunt. Op Tech Thorac Cardiovasc Surg. 2005;10:123-40.
8. Lemler M, Zellers T, Harris K, Ramaciotti C. Coarctation index: identification of recurrent coarctation in infants with hypoplastic left heart syndrome after the Norwood procedure. Am J Cardiol. 2000;86:697-9.

9. Fraisse A, Colan S, Jonas R, Gauvreau K, Geva T. Accuracy of echocardiography for detection of aortic arch obstruction after stage I Norwood procedure. Am Heart J. 1998;135:230-6.

10. Machii M, Becker A. Nature of coarctation in hypoplastic left heart syndrome. Ann Thorac Surg. 1995;59:1491-4.

11. Fraser C, Mee R. Modified Norwood procedure for hypoplastic left heart syndrome. Ann Thorac Surg. 1995;60(Suppl):S546-9. 